\title{
Extending the Classroom
}

\section{The Virtual Integrated Teaching and Learning Environment (VITLE)}

\author{
Alex C.W. Fung and Jenilyn Ledesma \\ Faculty of Social Sciences, Hong Kong Baptist University, Hong Kong \\ alexfing@hkbu.edu.hk
}

\begin{abstract}
This paper reports the case of an interactive, real time platform using webtechnology in the delivery of teaching and learning when classes were suspended during the Severe Acute Respiratory Syndrome (SARS) outbreak in April 2003 in Hong Kong. Responding to the suspension of schools during that unprecedented difficult period, the Hong Kong Baptist University offered schools free use of its Internet-based Virtual Integrated Teaching and Learning Environment (VITLE) platform. Teachers and their students were encouraged to adopt e-Learning by continuing their classes on the VITLE platform, and 75 schools registered to use the new technology. This is a specific example of taking advantage of streaming technologies to create a rich, multi-media communication solution for the benefits of the students, teachers and schools.
\end{abstract}

Key words: VITLE, real-time, synchronous, e-Learning, virtual classroom

\section{INTRODUCTION}

The past few years have seen an enormous growth in the accessibility of Internet technologies, especially the World Wide Web (WWW). The rise of the Internet as a communication medium continues to transform education, and teachers must now re-think how to conduct their teaching. The widespread availability of high speed Internet connections, such as broadband and digital subscriber lines (DSL), has allowed teachers to make greater use of these technologies. Real-time interactions with audio-video and multimedia features between teachers and students are already possible inside 'virtual classrooms' on the Internet. E-Learning is likely to be 
pervasive as the technology becomes more widespread and affordable, as this paper illustrates.

Advances in information and communications technology (ICT) have significantly changed the ways students learn, the ways teachers teach, and the means with which both parties access information (Leidner \& Jarvenpaa, 1993; Starr, 1997). In a traditional classroom, students learn from the physical delivery of lessons, which to a great extent depends on the teacher. In a virtual classroom, the delivery of lessons depends not only on the teacher but also on the technology used to deliver the teaching materials (Cyrs, 1994). With the increasing use of the virtual environment, technologies have become a critical component affecting teaching and learning effectiveness (Alavi, 1994; Sankar, Ford \& Terase, 1997); and students as well as instructors could become free from the time and space constraints of having to be in the same physical room, at the same time (Althaus, 1997; Barnard, 1997).

A more significant way with which the Internet has changed the dynamics of teaching and learning is to make possible direct teaching over distances. With this, a teacher could give instruction to students at any point in time through the Internet without having to meet face-to-face. Although video-conferencing facilities can be used for this purpose, the cost of doing so is prohibitive because both the teachers and students need to invest in the same set of specialized hardware and software. Moreover, the requirement of designated point-to-point connection with video-conferencing excludes the flexibility of access 'anywhere' as with the Internet.

This situation has changed drastically with the latest developments in Internet video-conferencing capabilities (Gale, 1994; Jacobs \& Rodgers, 1997; Kaye \& Medoff, 1999). With such capabilities, a teacher and her students located in different parts of the world can engage in a virtual class using standard personal computers and very affordable off-the-shelf hardware and software requirements (Porter, 1997; Riel, 2000). Students are no longer subjected to the constraints of geographical barriers in their quest for knowledge. Teachers are no longer restricted by physical distances in their attempt to give personal attention to students.

This paper illustrates the use of the Virtual Integrated Teaching and Learning Environment (VITLE) platform, which incorporates Internet videoconferencing, ICQ, and other interactive multi-media features in virtual classrooms to maintain teaching and learning in Hong Kong when classes were suspended due to the SARS outbreak. 


\section{BACKGROUND}

The outbreak of the severe acute respiratory syndrome in Hong Kong forced kindergartens, primary and secondary schools, and universities to suspend classes in March 2003 - which affected teaching and learning progress significantly. To enable students to continue with the lessons during the class suspension period, the Department of Education Studies (EDUC) and the School Administration and Management System (SAMS) Training and Research Unit of the Hong Kong Baptist University (HKBU) launched the 'Virtual Integrated Teaching and Learning Environment' (VITLE), a free new platform which breakthrough the limitations of physical classrooms during the class suspension period. The idea to launch VITLE was initiated by Dr. Alex Fung, Head of EDUC and Director of SAMS, and was made possible within 48 hours with the support of a number of sponsoring organizations ${ }^{2}$ from the business sector. Realizing the impact of such an unprecedented closure of schools on children and their families, the "Classes Suspended but Learning Continues" Initiative was officially launched on $1^{\text {st }}$ April 2003, enabling teachers to interact with their students and to conduct lessons through the web (SCMP, 2003a; 2003b; 2003c). The goal of the Initiative was to provide a territory-wide solution urgently not only to bring the disruption to kids' learning to a minimum, but also to confine them in a safe environment at home away from the danger of the contagious epidemic.

The University developed VITLE as part of its e-learning infrastructure since September 2002, and was due to conduct pilot tests in June 2003. But after the Hong Kong government decided to suspend classes in late March 2003, the need to continue education over the Internet was evident. As an elearning application, VITLE was made available to all primary and secondary schools the day classes were suspended so that teachers could stay in touch with their students in virtual classrooms while schools were closed. About 75 schools and thousands of students took part in the initiative, which also attracted international attention. As journalist Benny Evangelista wrote in the San Francisco Chronicle on April 21, 2003, "The Hong Kong example may be the first instance in which online learning has been used to replace real classrooms because of a major disruption in the education system." (San Francisco Chronicle, April 21, 2003). Macromedia chairman and chief executive Rob Burgess also said, "We are starting to see more and more examples of the Internet being used as a two-way communications medium, and Hong Kong Baptist University created a live virtual classroom where students were able to see the teacher on the screen literally conduct the class through this difficult time.

The sponsoring organisations included the Hong Kong Daily News, Cellwise Technologies Ltd., Macromedia Hong Kong Ltd., Microsoft HK Ltd., and PowerNet Internet Group. 
Knowing that some schools might not be able to run their own virtual classes for students, apart from providing the platform for schools to continue classes, the HKBU also launched the big virtual community education hall "HKBU VITLE Class' for all secondary and tertiary students as well as the general public. The number of registered participants with HKBU VITLE Class surged to 10,000 within the few weeks of operation. VITLE became one of the important communication channels for individual schools with their students during the outbreak of SARS in Hong Kong. For more information about the HKBU VITLE Classes, please visit http://www.ilearn.com.hk.

\section{VITLE: ARCHITECTURAL OVERVIEW}

The Virtual Integrated Teaching and Learning Environment (VITLE) is a web-based platform providing simultaneously on one screen in real-time mode the following features in support of teaching and learning: Video Broadcast (in three modes: teacher, teaching assistant, student), Interactive Question and Answer, Whiteboard, and Slide Presentation. The teacher can control the activation of the tools / features by clicking icons on the control panel. When a feature is turned OFF (by the teacher) the students will not see that particular function. This virtual environment is designed to model traditional classroom settings so that teachers can adapt to e-Teaching easily. Figure 1 shows the Teacher's View after logging in to a VITLE virtual classroom with a presentation slide loaded.

Basically, VITLE provides an interactive virtual classroom for teachers and students to meet in cyberspace. Each party needs only a multimedia PC (with an optional web-camera) and access to the Internet and hundreds of students can 'enter', i.e., log in to the room with the teacher together at the same time. Inside a VITLE virtual classroom, the student learns in real time:

1. with the teacher explaining over a web-camera;

2. with the slides shown by the teacher (with or without a transparency overlay);

3. with an electronic whiteboard; and

4. through Q\&A with the teacher similar to ICQ

Students equipped with a web-camera can also present themselves, as chosen by the teacher, inside the virtual classroom. A Teaching Assistant / Invited Guest Speaker can join in to team teach as well when given access by the teacher. Figure 2 below shows how the screen looks to a student. 


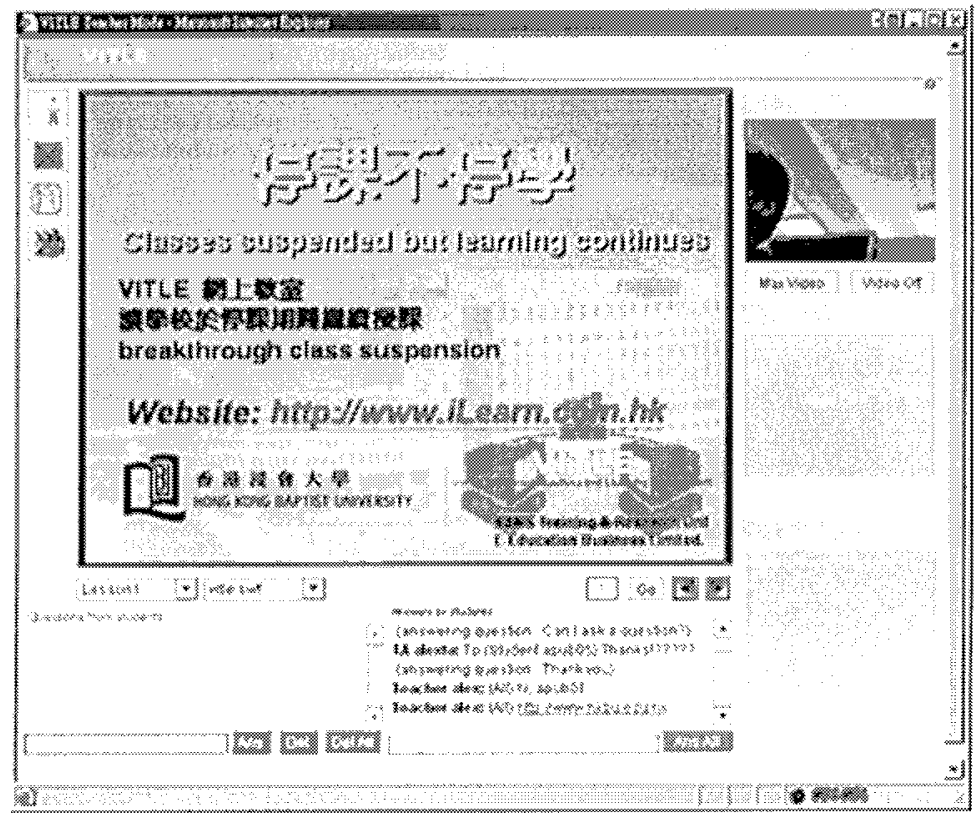

Figure 1. A Teacher's View inside the VITLE Virtual Classroom

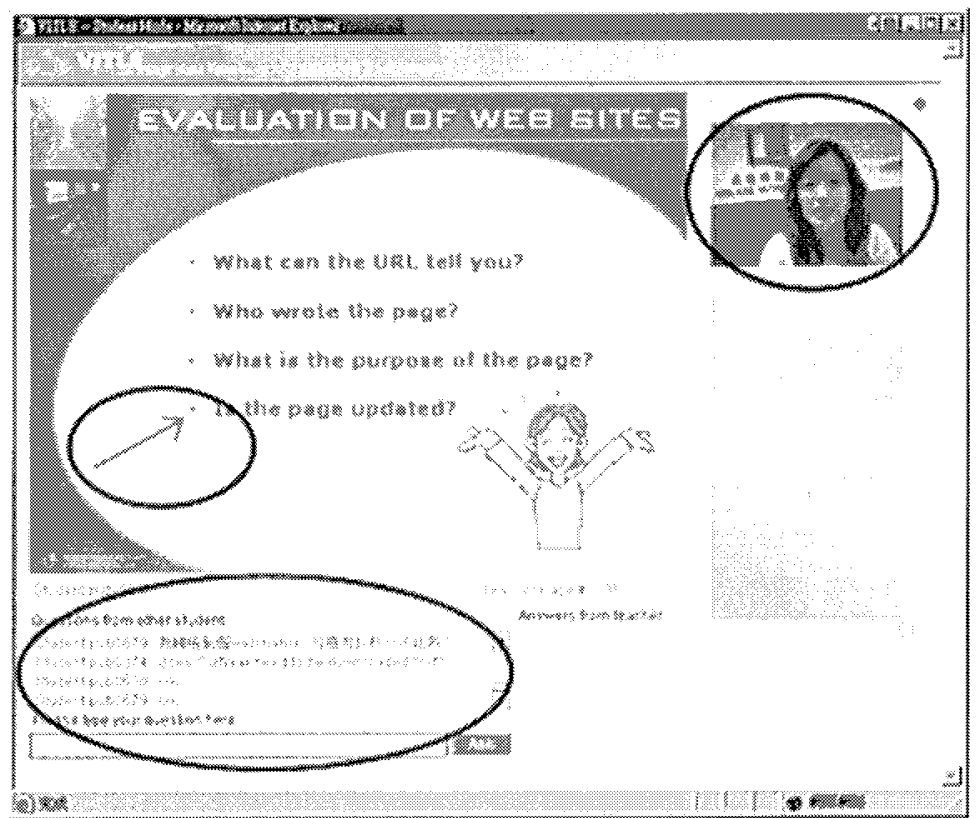

Figure 2. A Student's View inside the VITLE Virtual Classroom 
The implementation for VITLE uses the capabilities and ease of use of Macromedia Flash Communication Server MX 1.5 to provide unlimited concurrent access to all users. It comprises a web front-end which serves as an entrance to the platform, provides presentation files management, and is powered by Macromedia ColdFusion MX 1.5. Other Macromedia products used in conjunction included Macromedia Flash MX for connecting users to real-time data exchange server provided by Flash Communication Server (FCS). Multiple users can connect to the same application running on FCS which acts as a communication channel between the connected users. The web front-end is built from Macromedia ColdFusion MX. The operating system is Microsoft Windows 2000 Server with a Microsoft SQL 2000 Server. The hardware consisted of two servers (PIII Xenon $550 \times 4,2 \mathrm{~GB}$ ECC RAM).

VITLE allows for real-time, synchronous interaction between teachers and students who logon together in virtual classrooms. A teacher who is logged-on to the virtual environment can immediately begin teaching without the need for additional downloads and program installations. Students could watch their teachers (or even other students, if they had web cameras) live. All that was needed for them was a Web camera, a computer with Internet access, and a Macromedia Flash player (free software). As the streaming technology advances, VITLE makes virtual meetings possible anywhere at any time.

\section{USER FEEDBACK}

User feedback via telephone interview was collected from 9 schools using the VITLE platform. At the user level, both teachers and students perceived the platform to be useful and convenient as they could access it from any computer with access to the Internet. In short, VITLE has provided them access to learning like never before. They also preferred the platform because no special software and hardware equipment are required. However, they found some limitations with the platform. Some students commented that no 'archives' were available for downloading, so they were unable to view a missed programme. Another comment about the use of this platform was the technology. The sound quality and the video clarity were some of the issues raised. Another limitation was the necessity of converting Power Point slides to Flash files (in swf format). The Whiteboard, which only allows texts and arrows, was also limited. according to the comments received. Transmission delay was also another problem.

At the school level, the principals commented that the platform was relatively easy to use and learn. They also found the stability to be acceptable, and thought the platform could be really interactive particularly 
during remedial classes or tutorial sessions, or even as a communication channel between staff! They thought it had helped breakthrough the limitation of time and space, and was effective since lessons could also be conducted outside school hours. Because of the audio-visual presentation, lessons were richer and more vivid so helping increase students' concentration span. Self-learning amongst students was also actively promoted as a result of the opportunity provided by VITLE. The principals also mentioned that the platform helped enhanced teacher professionalism and confidence. It also provided them the opportunity to offer subjects beyond the school curriculum by integrating the use of IT. And since they have to prepare the materials before the session, teachers became more wellprepared and organised. Sharing also prevailed amongst the teachers, as they constantly discussed the subject matter.

However, some principals were concerned about the 'presence' of the students, and were unsure whether the students were 'attending' the lessons or not. Principals also perceived the process of converting Power Point files to 'swf' format as an additional workload and burden to teachers who were not computer literate. They also complained about problems with the Question and Answer Tool. For instance, only the teacher can choose which student's question to respond to. Likewise, the teacher also controls which student (and only one at a time) to appear live on screen. The students also had difficulty expressing themselves through written words, and were not fast enough in typing in the questions.

\section{SUMMARY}

The Severe Acute Respiratory Syndrome (SARS) struck badly in a number of regions in the world in 2003. The contagious and killing disease threatened and seriously interrupted different walks of life. In Hong Kong the SARS outbreak forced the suspension of schools for the whole month of April 2003, which significantly affected the teaching and learning progress of more than a million students. To enable students to continue with lessons during the class suspension period, Hong Kong Baptist University (HKBU) provided an e-learning solution to schools and teachers. Using virtual classrooms accessible on the VITLE platform via the Internet, teachers conducted lessons with students in the safety of their homes. VITLE became one of the important communication channels for individual schools to keep learning going for their students, and was a prime source of e-Learning for the community as well during the SARS crisis in Hong Kong.

VITLE was designed as an emergency alternative for schools to maintain a certain degree of teaching and learning for their students who could not physically attend classes during the SARS period. VITLE has also 
enabled Hong Kong education community to respond quickly to classroom suspension by providing an online learning community which allowed students to easily 'attend' classes with rich interactive functionality from the comfort of their own homes. The power and potential of using IT in education, especially for e-Learning, has been demonstrated. However, our experience has also sharply reflected the problem of the digital divide - the 'haves' and 'have-nots' - since only students with IT facilities at home and access to the Internet could be benefited. The project has also provided a test-bed for a large number of teachers and students to experiment and reflect upon their ways of teaching and styles of learning. Teaching in a virtual classroom is very different from that within a traditional classroom. What works and what doesn't for effective learning is yet very uncertain. Students' self-learning responsibility is undoubtedly a crucial factor, as they can choose to easily log out from an uninteresting lesson.

Schooling in the traditional sense implies attending classes and learning from the face-to-face delivery of lessons, which requires teachers and learners to be present physically at the same place at the same time. In contrast, VITLE virtual classrooms enable teachers and learners to attend classes in cyberspace, also interacting face-to-face, at the same time, but without having to be together at the same physical location. The VITLE platform is an impressive example of creating a rich, multimedia communications solution for e-Learning in virtual classrooms. This technology leads to different ways of communicating and processing information between teachers and learners, bringing about the potential for new forms of e-Teaching and e-Learning. It can be envisaged that the technology will be extended to applications of virtual rooms in a much broader sense for meetings of different kinds in cyberspace. In the not too distant future, the owning of a private virtual room may become as common as having an email account.

\section{THE WAY FORWARD}

The past decade has been a time of technological convergence. In the past, audio, video, text and film were different media relatively independent on their own. But now they are made compatible through digitization, which can be woven together into a single presentation (Webster, 1998; Webster \& Hackley, 1997). This paper demonstrates the promise of Internet videoconferencing technologies as a means for conducting distance education. The VITLE technology opens up new opportunities for students to study when, where and how they want. It has the potential of enhancing the teaching and learning experience through virtual classrooms. The platform is also a solution in ensuring that the continuity of teaching and learning is not 
jeopardized in light of any unforeseen crisis. Given the widespread availability of low-cost personal computers, and the widespread use of the Internet, it is plausible that this mode of distance education may partially replace face-to-face teaching sessions. The sessions can also become more stimulating since students can see or hear what is best for them, which in turn leads to a more efficient use of classroom time. More importantly, the benefits of the technological capabilities can potentially extend beyond physical classrooms to larger-scale distance education efforts.

ICT has permeated many aspects of education, and these technologies will continue to impact education in the future. Such technologies can certainly facilitate distance learning and teaching by helping to break geographical barriers. In the $21^{\text {st }}$ century when ICT is likely to play a critical role in enabling effective education, knowledge accumulated on existing and emerging technologies can guide us in terms of what technologies are appropriate under what circumstances. Rather than seeing technology as a solution to an existing problem, it is more fruitful to examine how the collection of ICT may complement each other to open up new and exciting possibilities for educating people.

\section{REFERENCES}

Alavi, M. (1994). Computer-mediated collaborative learning: An empirical evaluation. MIS Quarterly, 18(2), $159-174$.

Althaus, S. (1997). Computer-mediated communication in the university classroom: An experiment in on-line discussions. Communication Education, 46, 158-174.

Barnard, J. (1997). The World Wide Web and higher education: The promise of virtual universities and online libraries. Education Technology, 37(3), $30-35$.

Cyrs, T.E. (1994). Essential skills for college teaching. Las Cruces, NM: New Mexico State University.

Gale, S. (1994). Desktop video conferencing: Technical advances and evaluation issues. In: Stephen A.R. Scrivener (Ed.), Computer-supported cooperative work: The multimedia and networking paradigm. Aldershot, England: Avebury Technical.

Jacobs, G., \& Rodgers, C. (1997). Remote teaching with digital video: A trans-national experience. British Journal of Educational Technology, 28(4), $292-304$.

Kaye, B., \& Medoff, N. (1999). The world wide web: A mass communication perspective. Mountain View, CA: Mayfield.

Leidner, D.E., \& Jarvenpaa, S.L. (1993). The information age confronts education: Case studies on electronic classrooms. Information Systems Research, 4(1), $24-54$.

Porter, L.R. (1997). Creating the virtual classroom: Distance learning with the Internet. New York, NY: John Wiley.

Riel, M. (2000). The future of technology and education: Where are we heading? In D.M. Watson \& T. Downes (Eds.), Communications and networking in education. Boston, MA: Kluwer Academic Press, pp. $9-24$.

San Francisco Chronicle (2003). SARS crisis shows value of Internet education. Online platforms mean lessons can continue while schools are closed. April 21, 2003 (San Francisco Chronicle). 
Sankar, C.S., Ford, F.N., \& Terase, N. (1997). Impact of video conferencing in teaching an introductory MIS course. Journal of Educational Technology Systems, 26(1), 67 - 85 .

SCMP (2003a). Classes suspended but learning continues: HKBU helps to breakthrough class suspension with VITLE. March 31, 2003 (South China Morning Post).

SCMP (2003b). Technology keeps classes open for more than 60 Hong Kong schools April 18, 2003 (South China Morning Post).

SCMP (2003c). e-Learning brings classrooms to Hong Kong students. May 3, 2003 (South China Morning Post).

Starr, R.M. (1997). Delivering instruction on the World Wide Web: Overview and basic design practices. Educational Technology, 37(3), 7-15.

Webster, J. (1998). Desktop video conferencing: Experiences of complete users, wary users, and non-users. MIS Quarterly, 22(3), 257-286.

Webster, J., \& Hackley, P. (1997). Teaching effectiveness in technology-mediated distance learning. Academy of Management Journal, 40(5), 1282 - 1309. 